\title{
Cardiovascular Complication
}

National Cancer Institute

\section{Source}

National Cancer Institute. Cardiovascular Complication. NCI Thesaurus. Code C115199.

Any heart or vascular disorder occurring as a consequence of injury to the cardiovascular system. 